\title{
Understanding stability trends along the lanthanide series ${ }^{\mathrm{i}}$
}

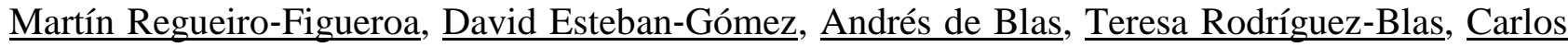 \\ Platas-Iglesias $^{*}$
}

Departamento de Química Fundamental, Universidade da Coruña, Campus da Zapateira, Rúa da Fraga 10, 15008 A Coruña (Spain)

Chemistry - A European Journal, volume 20, issue 14, pages 3974-3981, 01 April 2014

Received 14 November 2013, version of record online 27 February 2014, issue online 27 March 2014

This is the peer reviewed version of the following article:

Regueiro-Figueroa, Esteban-Gómez, D., de Blas, A., Rodríguez-Blas, T. and Platas-Iglesias, C. (2014), Understanding Stability Trends along the Lanthanide Series. Chem. Eur. J., 20: 3974-3981

which has been published in final form at https://doi.org/10.1002/chem.201304469. This article may be used for non-commercial purposes in accordance with Wiley Terms and Conditions for Use of Self-Archived Versions.

\begin{abstract}
The stability trends across the lanthanide series of complexes with the polyaminocarboxylate ligands TETA $^{4-}\left(\mathrm{H}_{4}\right.$ TETA=2,2',2",2'"'-(1,4,8,11-tetraazacyclotetradecane-1,4,8,11-tetrayl)tetraacetic acid), BCAED $^{4-} \quad\left(\mathrm{H}_{4} \mathrm{BCAED}=2,2^{\prime}, 2^{\prime \prime}, 2^{\prime \prime \prime}-\{[(1,4\right.$-diazepane-1,4-diyl)bis(ethane-2,1-diyl)]bis(azanetriyl) $\}$ tetraacetic acid), and $\quad \mathrm{BP}^{\prime} 18 \mathrm{C}^{2-}{ }^{2-}\left(\mathrm{H}_{2} \mathrm{BP} 18 \mathrm{C} 6=6,6^{\prime}-[(1,4,10,13\right.$-tetraoxa-7,16-diazacyclooctadecane-7, 16diyl)bis(methylene)]dipicolinic acid) were investigated using DFT calculations. Geometry optimizations performed at the TPSSh/6-31G(d,p) level, and using a $46+4 \mathrm{f}^{n} \mathrm{ECP}$ for lanthanides, provide bond lengths of the metal coordination environments in good agreement with the experimental values observed in the X-ray structures. The contractions of the $\mathrm{Ln}^{3+}$ coordination spheres follow quadratic trends, as observed previously for different isostructural series of complexes. We show here that the parameters obtained from the quantitative analysis of these data can be used to rationalize the observed stability trends across the $4 \mathrm{f}$ period. The stability trends along the lanthanide series were also evaluated by calculating the free energy for the reaction $[\mathrm{La}(\mathbf{L})]^{n+/}{ }_{(\text {sol })}+\mathrm{Ln}^{3+}{ }_{(\text {sol })} \rightarrow[\mathrm{Ln}(\mathbf{L})]^{n+/}{ }_{(\text {sol) }}+\mathrm{La}^{3+}{ }_{(\text {sol) }}$. A parameterization of the $\mathrm{Ln}^{3+}$ radii was performed by minimizing the differences between experimental and calculated standard hydration free energies. The calculated stability trends are in good agreement with the experimental stability constants, which increase markedly across the series for BCAED ${ }^{4-}$ complexes, increase smoothly for the TETA ${ }^{4-}$ analogues, and decrease in the case of $\mathrm{BP} 18 \mathrm{C}^{2-}{ }^{2-}$ complexes. The resulting stability trend is the result of a subtle balance between the increased binding energies of the ligand across the lanthanide series, which contribute to an increasing complex stability, and the increase in the absolute values of hydration energies along the $4 \mathrm{f}$ period.
\end{abstract}

Keywords: complex stability; computational chemistry; density functional calculations; lanthanides; ligand effects

\footnotetext{
*arlos.platas.iglesias@udc.es
} 


\section{Introduction}

The selective complexation of metal ions represents a coordination chemistry problem of great importance in different areas, ${ }^{[1]}$ including the design of metal complexes for diagnostic and imaging applications with lower toxicities, ${ }^{[2]}$ therapeutic agents for the treatment of metal intoxication, ${ }^{[3]}$ the preparation of selective metal extractants for hydrometallurgy, ${ }^{[4]}$ and the separation of metal ions (i.e., $\mathrm{Am}^{3+}$ and $\mathrm{Cm}^{3+}$ ) for nuclear waste management. ${ }^{[5]}$ The selective complexation of the trivalent lanthanide ions $\left(\mathrm{Ln}^{3+}\right)$ constitutes a particularly difficult problem, as they possess very similar physical and chemical properties. The $\mathrm{Ln}^{3+}$ ions behave as hard cations according to the classification of Pearson ${ }^{[6]}$ and they have similar radii, with the overall contraction of the ionic radius along the series from $\mathrm{La}^{3+}$ to $\mathrm{Lu}^{3+}$ being only approximately $16 \% .{ }^{[7]} \mathrm{In}$ addition, the trivalent actinide ions $\left(\mathrm{An}^{3+}\right)$ are also hard Lewis acids with the same charge and similar ionic radius. As a result, both the separation of $\mathrm{Ln}^{3+}$ ions into individual elements and the separation of the $\mathrm{Ln}^{3+}$ and $\mathrm{An}^{3+}$ ions for nuclear waste management represent difficult tasks. ${ }^{[8]}$

The stable complexation of $\mathrm{Ln}^{3+}$ ions in aqueous solutions is often achieved with either non-macrocyclic poly(aminocarboxylate) ligands such as ethylenediaminetetraacetic acid $\left(\mathrm{EDTA}^{4-}\right)$ and diethylene triamine pentaacetic acid $\left(\mathrm{DTPA}^{5-}\right)$, and macrocyclic homologues such as 1,4,7,10-tetraazacyclododecane-1,4,7,10tetraacetic acid (DOTA ${ }^{4-}$; Scheme 1) ${ }^{[9]}$ The stability of the corresponding $\mathrm{Ln}^{3+}$ complexes often increases from $\mathrm{La}^{3+}$ to $\mathrm{Lu}^{3+}$ along the lanthanide series owing to the increased charge density of the metal ion. This is, for instance, the case of the $\left[\operatorname{Ln}(\mathrm{EDTA})\left(\mathrm{H}_{2} \mathrm{O}\right)_{q}\right]^{-}$complexes, for which the stability constants increase by four orders of magnitude across the lanthanide series $\left(\log K_{\mathrm{LuEDTA}}-\log K_{\mathrm{LaEDTA}}=4.34\right) .{ }^{[10]}$ It has been shown that this trend can be magnified by increasing the length of the ethylene spacer of EDTA $^{4-}$ with a 1,4dimethyl-1,4-diazepane, to give $\mathrm{BCAED}^{4-}\left(\mathrm{H}_{4} \mathrm{BCAED}=2,2^{\prime}, 2^{\prime \prime}, 2^{\prime \prime \prime}-\{[(1,4\right.$-diazepane-1,4-diyl)bis(ethane-2,1diyl)]bis(azanetriyl) \}tetraacetic acid; Scheme 1, see also Figure 1). The stability of the complexes with this ligand show an impressive increase across the series, the $\mathrm{Lu}^{3+}$ complex being eight orders of magnitude more stable than the $\mathrm{La}^{3+}$ homologue $\left(\log K_{\mathrm{LuBCAED}}-\log K_{\mathrm{LaBCAED}}=8.2\right) .{ }^{[1]}$

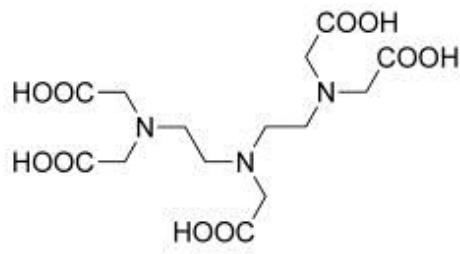

H5TPA<smiles>O=C(O)CN(CCN(CC(=O)O)CC(=O)O)CC(=O)O</smiles>

$\mathrm{H}_{4}$ EDTA<smiles>O=C(O)CN(CCN1CCCN(CCN(CC(=O)O)CC(=O)O)CC1)CC(=O)O</smiles>

$\mathrm{H}_{4}$ BCAED

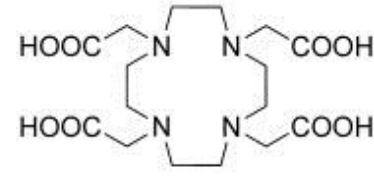

$\mathrm{H}_{4}$ DOTA

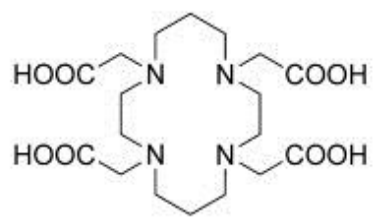

$\mathrm{H}_{4}$ TETA

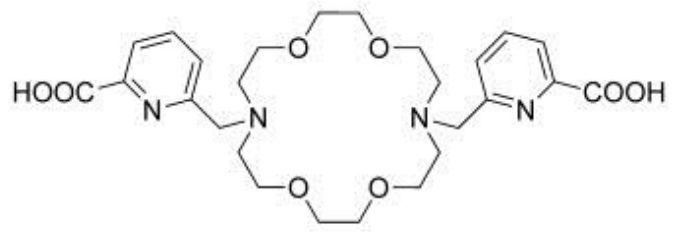

$\mathrm{H}_{2} \mathrm{BP} 18 \mathrm{C} 6$

Scheme 1. Ligands discussed in the present work. 


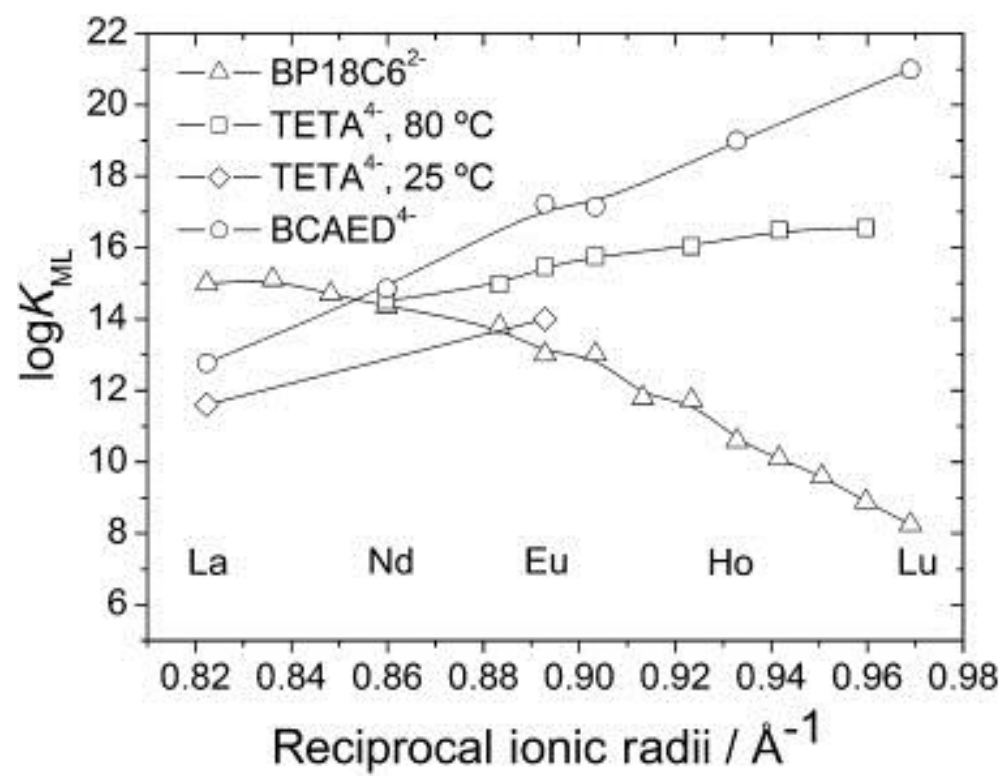

Figure 1. Variation of the stability constants ( $\log K_{\mathrm{ML}}$ values) across the lanthanide series for different $\mathrm{Ln}^{3+} \operatorname{complexes}$ with polyaminocarboxylate ligands. The solid lines are simply a guide for the eye. Ionic radii were taken from Ref.

7 assuming coordination number 9 .

For a second class of ligands, such as DTPA ${ }^{5-}$ derivatives, the stability of the corresponding $\mathrm{Ln}^{3+}$ complexes increases across the series, reaches a plateau, and then declines, ${ }^{[12]}$ which probably reflects an increased steric strain for the smallest $\mathrm{Ln}^{3+}$ ions. Finally, a reduced group of ligands, such as diaza[18]crown- $6^{[13]}$ and diaza[15]crown- $5^{[14]}$ derivatives that contain different pendant arms, form complexes with decreasing stability across the lanthanide series. Among this group, BP18C6 ${ }^{2-}\left(\mathrm{H}_{2} \mathrm{BP} 18 \mathrm{C} 6=6,6^{\prime}-[(1,4,10,13\right.$-tetraoxa7,16-diazacyclooctadecane-7,16-diyl)bis(methylene)]dipicolinic acid) was shown to provide an unprecedented selectivity for the large lanthanide ions $\left(\log K_{\mathrm{CeBP} 18 \mathrm{CC}}-\log K_{\mathrm{LuBP} 18 \mathrm{C} 6}=6.9\right) .{ }^{[15]}$

The computational treatment of lanthanide complexes still represents a challenging task for computational chemists. For instance, a limited number of semiempirical or empirical methods are available for these systems. ${ }^{[16]}$ Moreover, the computational modeling of compounds that contain such heavy atoms requires an adequate treatment of relativistic effects, and for some purposes spin-orbit coupling. ${ }^{[17]}$ However, the emergence of different computational approaches, such as the methods based on density functional theory (DFT), and the development of relativistic and quasi-relativistic effective core potentials for elements below the third period of the periodic table ${ }^{[18]}$ has facilitated the growth of theoretical studies in this area.

Herein, we report a DFT study that aims to understand the reasons behind the different stability trends observed for $\mathrm{Ln}^{3+}$ complexes in aqueous solution. For this purpose, we have investigated the $[\mathrm{Ln}(\mathrm{BCAED})]^{-}$and $[\mathrm{Ln}(\mathrm{BP} 18 \mathrm{C} 6)]^{+}$complexes, which present the largest size discrimination of $\mathrm{Ln}^{3+}$ ions reported to date, as well as opposite stability trends. As a representative example of those systems providing a conventional behavior across the lanthanide series, we have chosen the [Ln(TETA) $]^{-}$ $\left(\mathrm{H}_{4}\right.$ TETA=2,2',2",2'"'-(1,4,8,11-tetraazacyclotetradecane-1,4,8,11-tetrayl)tetraacetic acid) complexes (Figure $1){ }^{[19,20]}$ which have been structurally characterized using X-ray crystallography ${ }^{[21,22]}$ and do not contain coordinated water molecules such as the DOTA $^{4-}$ analogues. The results reported herein provide a new methodology for predicting size-discrimination effects for $\mathrm{Ln}^{3+}$ ions and therefore aid ligand design for specific applications. 


\section{Computational Methods}

All calculations were performed by employing DFT within the hybrid meta-generalized gradient approximations (meta-GGA) with the TPSSh exchange-correlation functional, ${ }^{[23]}$ and the Gaussian 09 package (Revision A.02). ${ }^{[24]}$ We have selected the TPSSh functional on the basis of previous studies that showed it provides more accurate geometries of $\mathrm{Ln}^{3+}$ complexes than the popular B3LYP functional, ${ }^{[25]}$ as well as accurate ${ }^{17} \mathrm{O} A_{\text {iso }}$ values of the coordinated water molecule for different $\mathrm{Gd}^{3+}$ complexes with polyaminocarboxylate ligands. ${ }^{[26]}$ Full geometry optimizations of the $[\operatorname{Ln}(\mathrm{TETA})]^{-},[\operatorname{Ln}(\mathrm{BCAED})]^{-}$, and [Ln(BP18C6)] ${ }^{+}$systems ( $\mathrm{Ln}=\mathrm{La}, \mathrm{Ce}, \mathrm{Nd}, \mathrm{Gd}, \mathrm{Tm}$, or $\left.\mathrm{Lu}\right)$ were performed by using the large-core relativistic effective core potential (LCRECP) of Dolg et al. and the related [5s4p3d]-GTO valence basis set for the lanthanides, ${ }^{[27]}$ and the standard $6-31 \mathrm{G}(\mathrm{d}, \mathrm{p})$ basis set for $\mathrm{C}, \mathrm{H}, \mathrm{N}$, and $\mathrm{O}$ atoms. This LCRECP includes $46+4 \mathrm{f}^{n}$ electrons in the core for the lanthanide, thus leaving the outermost 11 electrons $(5 \mathrm{~s}, 5 \mathrm{p}, 5 \mathrm{~d}$, and $6 \mathrm{~s})$ to be treated explicitly. The use of LCRECP has been justified by the fact that $4 \mathrm{f}$ orbitals do not significantly contribute to bonding owing to their limited radial extension relative to the $5 \mathrm{~d}$ and $6 \mathrm{~s}$ shells ${ }^{[28,29]}$ LCRECP calculations were shown to provide good results in DFT studies that focus on the structure, dynamics, and estimates of relative energies of $\mathrm{Ln}^{3+}$ complexes. ${ }^{[30]}$ Since LCRECP calculations include the $4 \mathrm{f}$ electrons in the core, they were conducted on a pseudosinglet state configuration. No symmetry constraints were imposed during the optimizations. The default values for the integration grid (75 radial shells and 302 angular points) and the self-consistent field (SCF) energy convergence criteria $\left(10^{-8}\right)$ were used in all calculations. The stationary points found on the potential-energy surfaces as a result of the geometry optimizations have been tested to represent energy minima rather than saddle points by means of frequency analysis. Gibbs free energies were obtained at $T=298.15 \mathrm{~K}$ within the harmonic approximation.

Solvent effects (water) were evaluated by using the polarizable continuum model (PCM) in which the solute cavity is built as an envelope of spheres centered on atoms or atomic groups with appropriate radii. In particular, we used the integral equation formalism (IEFPCM $)^{[31]}$ variant as implemented in Gaussian 09 with the radii and nonelectrostatic terms obtained by Truhlar et al. (SMD solvation model). ${ }^{[32]}$ In the SMD model the boundary between the solute cavity and the solvent continuum is defined to enclose a superposition of nuclear-centered spheres with a given intrinsic Coulomb radii. A key point of the present study is the accurate calculation of hydration free energies of the $\mathrm{Ln}^{3+}$ ions. Thus, the lanthanide radii used for SMD calculations were parameterized by minimizing the differences between the experimental and calculated hydration free energies for the reaction [Eq. (1)]: ${ }^{[33]}$

$$
\mathrm{Ln}^{3+}{ }_{(\mathrm{g})} \rightleftharpoons \mathrm{Ln}^{3+}{ }_{(\mathrm{sol})}
$$

Since hydration free energies used a gas-phase standard state of $1 \mathrm{~atm}$, the standard hydration free energy was calculated by taking into account the concentration change between the gas-phase standard state $(P=1$ atm) and the liquid-state standard state $\left(1 \mathrm{~mol} \mathrm{~L}^{-1}\right)$ [Eq. (2)]:

$$
\Delta G_{\text {hyd }}^{\circ}=\Delta G_{\text {sol }}+R T \ln \left(M_{\text {sol }} / M_{\mathrm{g}}\right)
$$

The second term in Equation (2) equals $1.87 \mathrm{kcal} \mathrm{mol}^{-1}$ for $T=298.15 \mathrm{~K}, P=1 \mathrm{~atm}$, and $M_{\mathrm{sol}}=1 \mathrm{M}$. 
The PCM radii obtained at the TPSSh/LCRECP level and the corresponding hydration free energies are given in Table 1. The optimized PCM radii and the ionic radii of the trivalent $\mathrm{Ln}^{3+}$ ions provide a linear relationship $\left(R^{2}=0.998\right.$; Figure $\mathrm{S} 1$ in the Supporting Information), which supports the reliability of both the calculated radii and the LCRECP approach. Furthermore, calculations performed with the popular hybridGGA functionals B3LYP and B3PW91, and the hybrid meta-GGA functional M06 provide hydration free energies that are in very good agreement with the experimental values. An excellent agreement between experimental and calculated $\Delta G^{\circ}$ hyd values is also observed with MP2 calculations in combination with the LCRECP approach, and with TPSSh calculations together with the all-electron second-order Douglas-KrollHess (DKH2) method and the all-electron scalar relativistic basis set of Pantazis and Neese. ${ }^{[35]}$ Somewhat larger deviations from the experimental values were found when using the small-core relativistic effective core potential (SCRECP) approach in combination with the associated ECP28MWB_GUESS basis set. ${ }^{[36]}$ Overall, these results indicate that the PCM radii reported in Table 1 can be used confidently with different functionals in combination with RECPs or all-electron relativistic approaches. The PCM radii given in Table 1 were subsequently used for the calculations performed on the $[\operatorname{Ln}(\mathrm{TETA})]^{-},[\operatorname{Ln}(\mathrm{BCAED})]^{-}$, and $[\operatorname{Ln}(\mathrm{BP} 18 \mathrm{C} 6)]^{+}$systems. No scaling factor was applied to the PCM radii for the calculation of the electrostatic interactions $(\alpha=1.0)$.

Basis-set superposition errors (BSSEs), which are an undesirable consequence of using finite basis sets that leads to an overestimation of the binding energy, were calculated using the standard Counterpoise method $^{[37]}$ with calculations performed in the gas phase. ${ }^{[38]}$

Table 1. Parameterized PCM radii and ionic radii $[\AA]$ for $\mathrm{Ln}^{3+}$ ions and comparison of experimental and calculated hydration free energies $\left[\mathrm{kcal} \mathrm{mol}^{-1}\right]$.

\begin{tabular}{|c|c|c|c|c|c|c|c|c|c|}
\hline & $\begin{array}{l}\text { PMC } \\
\text { radii }\end{array}$ & $\begin{array}{c}\text { Ionic } \\
\text { radii }^{[a]}\end{array}$ & $\operatorname{Exptl}^{[\mathrm{b}]}$ & B3LYP/LC & B3PW91/LC & $\begin{array}{c}\Delta G_{\text {hyd }}^{\circ} \\
\text { M06/LC }\end{array}$ & MP2/LC & TPSSh/SC & TPSSh/DKH2 \\
\hline $\mathrm{La}$ & 1.874 & 1.216 & -788.1 & -787.8 & -787.6 & -787.6 & -787.8 & -790.9 & -787.9 \\
\hline $\mathrm{Ce}$ & 1.840 & 1.196 & -802.4 & -802.5 & -802.2 & -802.3 & -802.4 & -806.1 & -799.8 \\
\hline $\operatorname{Pr}$ & 1.822 & 1.179 & -810.1 & -810.3 & -810.1 & -810.1 & -810.2 & -815.0 & -810.5 \\
\hline $\mathrm{Nd}$ & 1.808 & 1.163 & -816.5 & -816.4 & -816.2 & -816.2 & -816.3 & -819.6 & -816.5 \\
\hline $\mathrm{Sm}$ & 1.770 & 1.132 & -833.5 & -833.8 & -833.6 & -833.6 & -833.7 & -836.7 & -833.9 \\
\hline $\mathrm{Eu}$ & 1.755 & 1.120 & -841.1 & -840.9 & -840.7 & -840.7 & -840.8 & -843.6 & -838.5 \\
\hline Gd & 1.746 & 1.107 & -845.2 & -845.1 & -844.9 & -845.0 & -845.0 & -847.9 & -845.0 \\
\hline $\mathrm{Tb}$ & 1.735 & 1.095 & -850.5 & -850.4 & -850.2 & -850.2 & -850.2 & -852.8 & -850.4 \\
\hline Dy & 1.715 & 1.083 & -859.9 & -860.3 & -860.1 & -860.2 & -860.2 & -862.7 & -860.3 \\
\hline Ho & 1.710 & 1.072 & -862.7 & -862.7 & -862.5 & -862.5 & -862.5 & -864.8 & -862.6 \\
\hline Er & 1.701 & 1.062 & -867.4 & -867.2 & -867.0 & -867.0 & -867.2 & -869.0 & -867.1 \\
\hline $\mathrm{Tm}$ & 1.681 & 1.052 & -877.3 & -877.5 & -877.3 & -877.3 & -877.3 & -879.4 & -877.4 \\
\hline $\mathrm{Yb}$ & 1.668 & 1.042 & -884.1 & -884.3 & -884.1 & -884.1 & -884.1 & -894.9 & -884.3 \\
\hline $\mathrm{Lu}$ & 1.659 & 1.032 & -888.1 & -888.9 & -888.7 & -888.7 & -888.7 & -889.7 & -888.8 \\
\hline
\end{tabular}

[a] Data for coordination number 9 from Ref. 7. [b] Experimental data from Ref. 34 corrected as described in Ref. 33. 


\section{Results and discussion}

\section{Optimized geometries}

The solution structure of the $[\operatorname{Ln}(\mathrm{BP} 18 \mathrm{C} 6)]^{+}$complexes has been investigated in detail by using NMR spectroscopy and DFT calculations at the B3LYP/LCRECP/6-31G(d) level. ${ }^{[15]}$ Our calculations performed with the TPSSh functional provide Ln-donor distances somewhat shorter than those obtained with B3LYP, which is in line with our previous computational studies. ${ }^{[25]}$ The TPSSh/LCRECP/6-31G(d,p) calculations provide a minimum energy conformation that corresponds to the $\Delta(\delta \lambda \delta)(\delta \lambda \delta)$ isomer, which is in agreement with the analysis of the ${ }^{1} \mathrm{H}$ NMR spectroscopic paramagnetic shifts induced by $\mathrm{Ce}^{3+}$ and $\operatorname{Pr}^{3+} \cdot{ }^{[15]} \mathrm{The}^{2}$ optimized geometries of $[\mathrm{Ln}(\mathrm{BP} 18 \mathrm{C} 6)]^{+}$complexes present nearly undistorted $C_{2}$ symmetries (Figure 2, see also Table $\mathrm{S} 1$ in the Supporting Information).
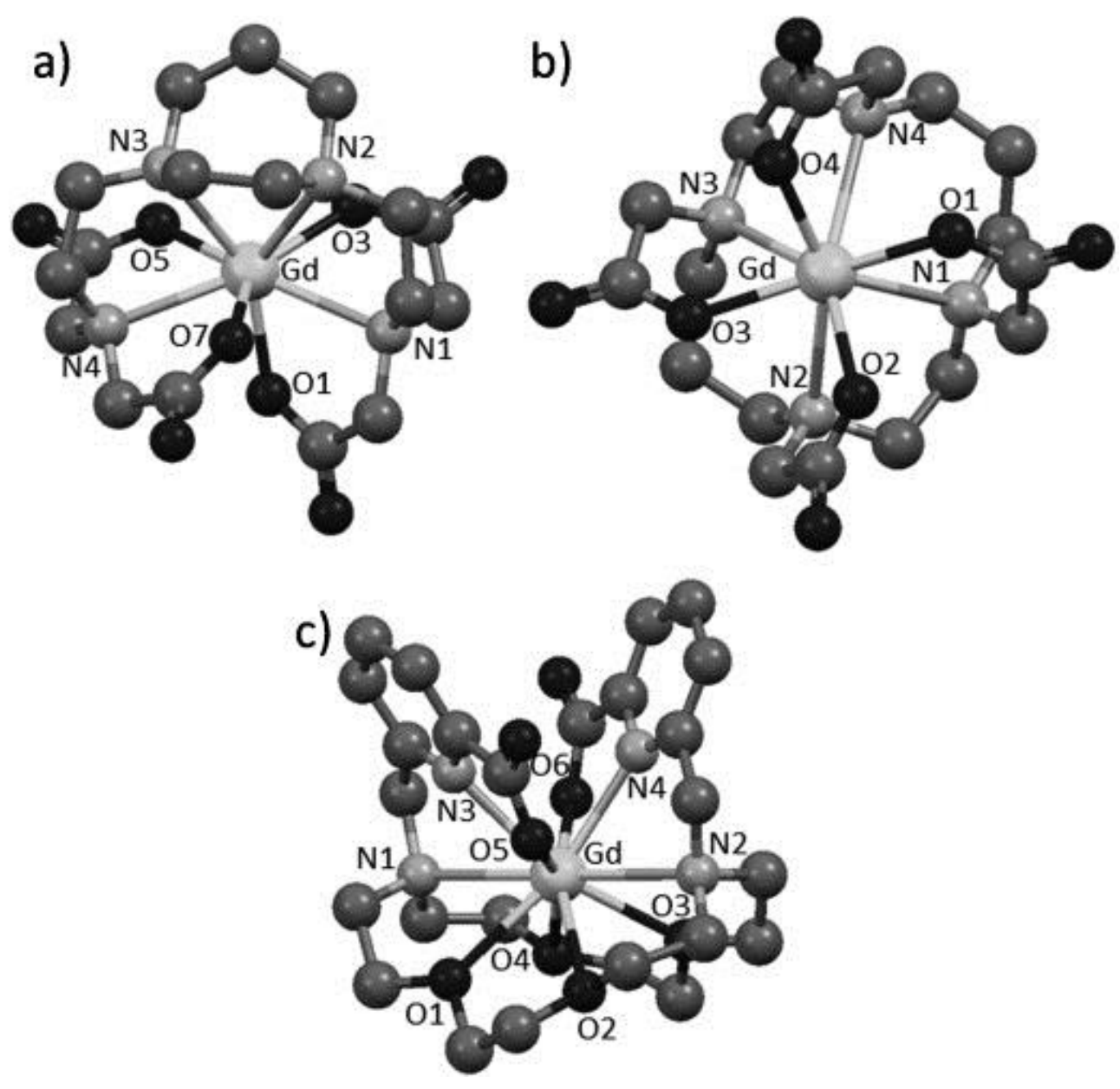

Figure 2. Structures of the a) $[\mathrm{Gd}(\mathrm{BCAED})]^{-}$, b) $[\mathrm{Gd}(\mathrm{TETA})]^{-}$, and c) $[\mathrm{Gd}(\mathrm{BP} 18 \mathrm{C6})]^{+}$complexes optimized in aqueous solution at the TPSSh/LCRECP/6-31G(d,p) level. Hydrogen atoms have been omitted for clarity.

The optimized structures of [Ln(TETA) $]^{-}$complexes also show nearly undistorted $C_{2}$ symmetries (Figure 2). The distances between the $\mathrm{Gd}^{3+}$ ion and the donor atoms of the ligand in $[\operatorname{Ln}(\mathrm{TETA})]^{-}$are in reasonably good agreement with those observed in the solid state for the $\mathrm{Eu}^{3+}$ analogue, ${ }^{[22]}$ with an unsigned mean deviation of $3.8 \%$. The agreement between the experimental and calculated $\mathrm{Ln}-\mathrm{O}$ distances is excellent $(<0.05 \AA)$, with the main difference between the experimental and calculated distances being the overestimation of the Ln-N distances in the calculated structures by approximately $0.15 \AA$. A similar trend can be observed by comparing the experimental and calculated structures of [Gd(BCAED)] ${ }^{-}$(see Tables S2 
and S3 in the Supporting Information) with an unsigned mean deviation of $2.1 \%$. The overestimation of the Ln-N bond lengths can be ascribed to two effects: 1) the fact that LCRECP calculations provide bond lengths approximately $0.02-0.07 \AA$ longer than the corresponding small-core calculations; ${ }^{[28,39]}$ and 2 ) the overestimation of the $\mathrm{Ln}-\mathrm{N}$ donor distances often observed for geometries optimized in the gas phase with respect to those optimized in aqueous solution. ${ }^{[40,41]}$ In spite of these limitations, LCRECP calculations have been shown to provide valuable information on the structure, dynamics, and energetics of many $\operatorname{Ln}^{3+}$ complexes. ${ }^{[30,42]}$
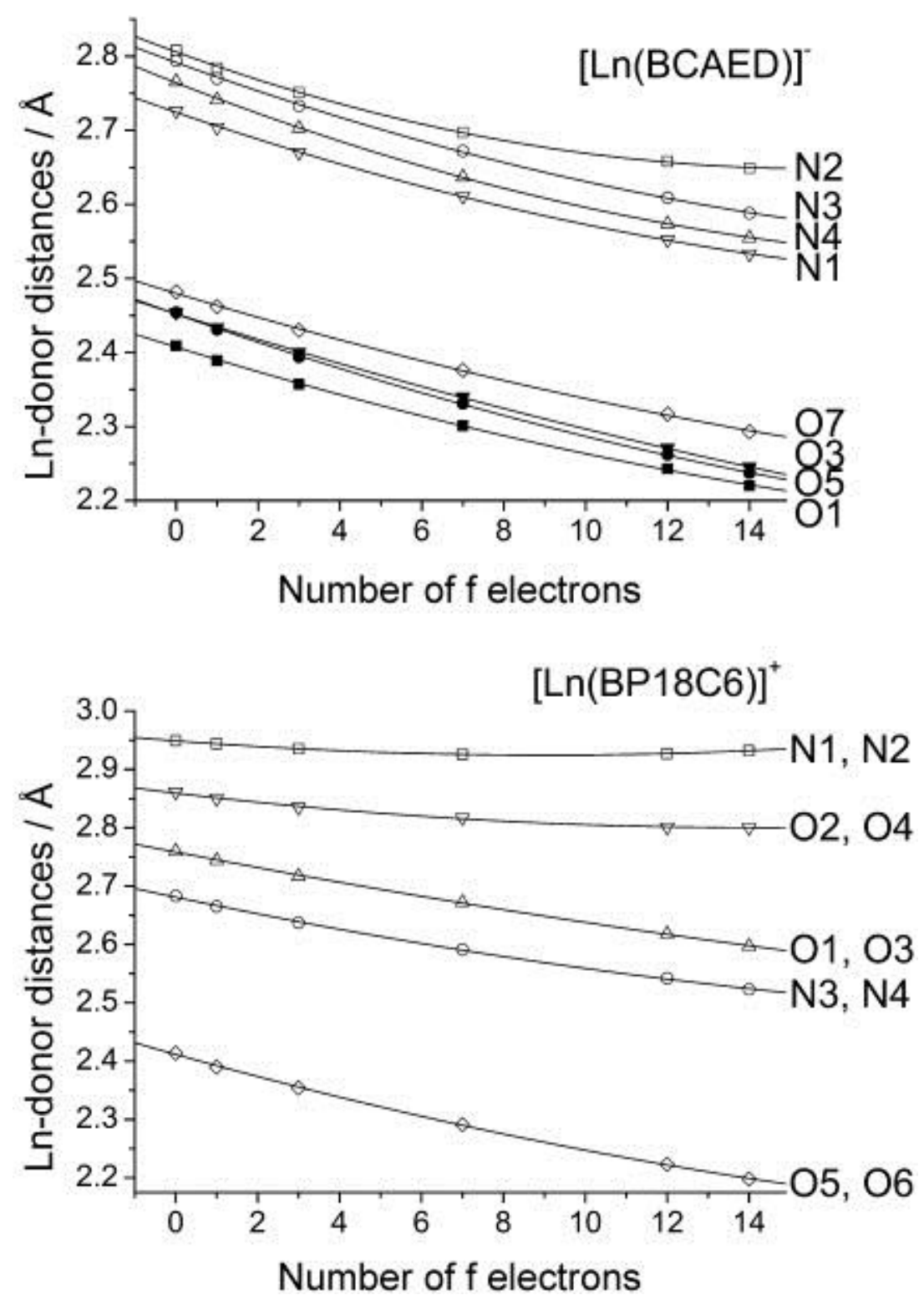

Figure 3. Variation of the calculated bond lengths of the metal coordination environments for $[\operatorname{Ln}(\mathrm{BCAED})]^{-}$and $[\mathrm{Ln}(\mathrm{BP} 18 \mathrm{C} 6)]^{+}$complexes at the TPSSh/LCRECP/6-31G(d,p) level. See Figure 2 for labeling. The solid lines represent quadratic fits of the data to $y=a+b x+c x^{2}$ with $R^{2}>0.999$.

A careful analysis of the bond lengths of the $\mathrm{Ln}^{3+}$ coordination environments across the lanthanide series provides some insight into the stability trends observed for this series of complexes (Figure 3, see also Figure $\mathrm{S} 2$ in the Supporting Information). Indeed, the $\mathrm{Ln}$-donor distances in $[\mathrm{Ln}(\mathrm{BCAED})]^{-}$complexes decrease sharply across the lanthanide series as should be expected according to the lanthanide contraction. A similar 
situation is observed for [ $\operatorname{Ln}($ TETA $)]^{-}$complexes, although we notice that 1$)$ the average $\mathrm{Ln}-\mathrm{N}$ bond lengths are longer for $[\operatorname{Ln}(\mathrm{TETA})]^{-}$than in $[\operatorname{Ln}(\mathrm{BCAED})]^{-}$, and 2) some of the $\mathrm{Ln}-\mathrm{N}$ distances in $[\operatorname{Ln}(\mathrm{TETA})]^{-}$ complexes such as Ln-N2 and Ln-N4 decrease only moderately along the lanthanide series from 2.864 (La) to $2.779 \AA$ (Lu). This represents a contraction of these bond lengths of only $0.085 \AA$, whereas the contraction of the Ln-N1 and Ln-N3 distances is considerably more important $(0.150 \AA)$. In the case of [Ln(BP18C6) $]^{+}$ complexes, this effect is even more important, with the Ln-N1 and Ln-N2 distances decreasing slightly from $\mathrm{La}$ to $\mathrm{Gd}$, and then increasing along the second half of the lanthanide series. In addition, the $\mathrm{Ln}-\mathrm{O} 2$ and $\mathrm{Ln}-$ O4 distances experience a contraction of only $0.061 \AA$ across the series. These geometrical data indicate that the structural correspondence between the binding sites offered by the ligand and the small $\mathrm{Ln}^{3+}$ ions follows the trend $\mathrm{BCAED}^{4-}>\mathrm{TETA}^{4-}>\mathrm{BP} 18 \mathrm{C}^{2-}{ }^{2-}$ which is in accordance with the experimental stability trends.

Raymond et al. ${ }^{[43]}$ reported a detailed investigation of the X-ray structures of isostructural $\mathrm{Ln}^{3+}$ complexes that showed that the average bond lengths decrease quadratically along the series. Subsequent computational investigations of the $\left[\mathrm{Ln}\left(\mathrm{H}_{2} \mathrm{O}\right)_{9}\right]^{3+}$ and $\left[\mathrm{Ln}\left(\mathrm{H}_{2} \mathrm{O}\right)_{8}\right]^{3+}$ species also revealed a quadratic decrease in the $\mathrm{Ln}-$ $\mathrm{OH}_{2}$ bond lengths across the $4 \mathrm{f}$ period. ${ }^{[44]}$ The bond lengths of the metal coordination environment in the three series of complexes investigated here indeed follow quadratic trends with respect to the number of $4 \mathrm{f}$ electrons of the $\mathrm{Ln}^{3+}$ ion (Figure 3). The average bond lengths of the $\mathrm{Ln}^{3+}$ coordination sphere also follow the expected quadratic trend (Figure 4), thus providing the fitting parameters shown in Table 2. The results of the quadratic fits of the data reported previously for $\left[\mathrm{Ln}\left(\mathrm{H}_{2} \mathrm{O}\right)_{8}\right]^{3+}$ are also given in Table 2 as a representative example of a series of complexes with an unconstrained coordination environment. ${ }^{[45]}$ Following the work of Raymond et al., the fitting parameters $b$ and $c$ were normalized by applying a scaling factor of $1 / a{ }^{[43]}$ The fitting parameters obtained in the present work are very similar to those reported by Raymond et al. for different series of isostructural $\mathrm{Ln}^{3+}$ complexes, which confirms the validity of our approach. The scaled parameters $b^{*}$ and $c^{*}$ show a uniform variation for the three series of complexes, so that $b^{*}$ becomes more negative and $c^{*}$ increases following the sequence $\mathrm{BP} 18 \mathrm{C}^{2-} \rightarrow \mathrm{TETA}^{4-} \rightarrow \mathrm{BCAED}^{4-}$. Both $b^{*}$ and $c^{*}$ approach the values obtained for $\left[\mathrm{Ln}\left(\mathrm{H}_{2} \mathrm{O}\right)_{8}\right]^{3+}$ following this sequence, which is also reflected in the values of $c$ and $b$. Thus, an increased constraint for the coordination of the ligand to the $\mathrm{Ln}^{3+}$ ions across the $4 \mathrm{f}$ period is reflected in more negative $b^{*}$ values and more positive $c^{*}$ parameters. The variation in these parameters for the ligands investigated here parallels the stability trends observed along the $4 \mathrm{f}$ period.

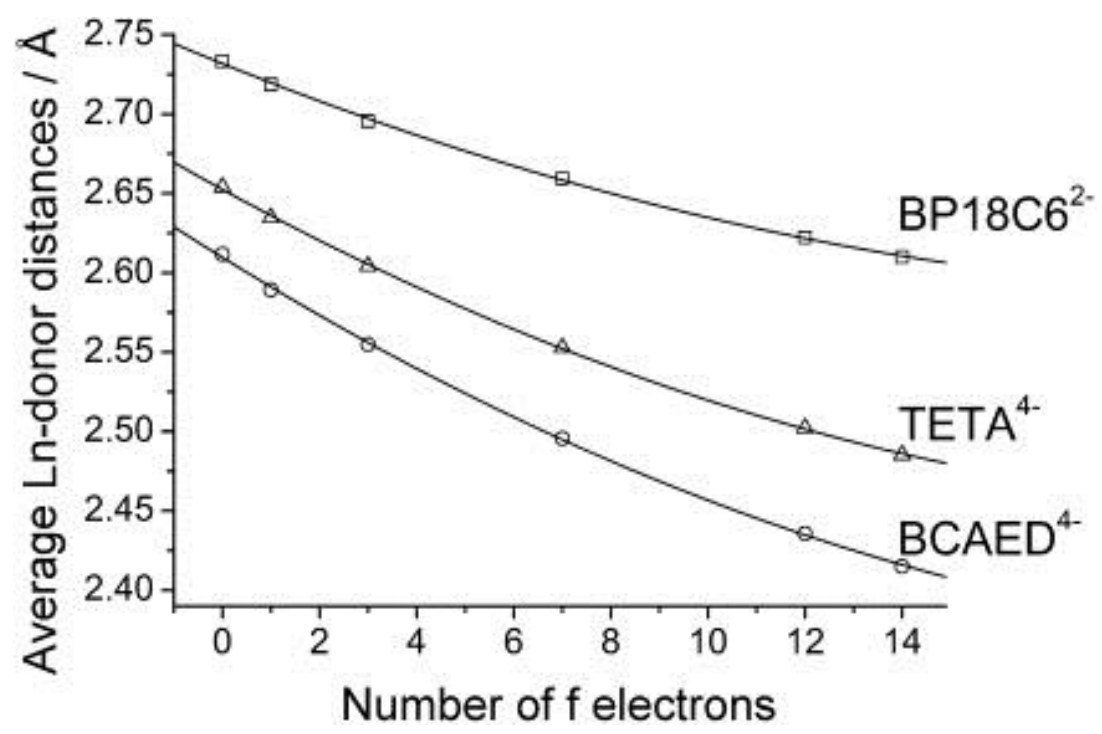

Figure 4. Variation of the average calculated bond lengths of the metal coordination environments for [Ln(BCAED)] ${ }^{-}$, $[\operatorname{Ln}(\mathrm{TETA})]^{-}$, and $[\operatorname{Ln}(\mathrm{BP} 18 \mathrm{C} 6)]^{+}$complexes at the TPSSh/LCRECP/6-31G(d,p) level. The solid lines represent quadratic fits of the data according to $y=a+b x+c x^{2}$ with $R^{2}>0.999$. 
Table 2. Results of the quadratic fits $\left(y=a+b x+c x^{2}\right)$ for the Ln-donor lengths calculated for different series of complexes. ${ }^{[a]}$

\begin{tabular}{lllll}
\hline & BP18C6 $^{2-}$ & TETA $^{4-}$ & BCAED $^{4-}$ & {$\left[\mathbf{L n}\left(\mathbf{H}_{\mathbf{2}} \mathbf{O}\right)_{\mathbf{8}}\right]^{3+}$} \\
\hline$a(\sigma)$ & $2.732(1)$ & $2.652(1)$ & $2.610(2)$ & $2.556(2)$ \\
$10^{2} b(\sigma)$ & $-1.23(5)$ & $-1.68(6)$ & $-1.90(6)$ & $-2.04(6)$ \\
$10^{4} c(\sigma)$ & $2.62(38)$ & $3.48(34)$ & $3.66(45)$ & 3.92 \\
$10^{3} b^{*}=b / a$ & -4.510 & -6.332 & -7.266 & -7.997 \\
$10^{4} c^{*}=c / a$ & 0.960 & 1.313 & 1.401 & 1.532 \\
$10^{2} c / b$ & -2.13 & -2.08 & -1.93 & -1.92 \\
$R^{2}$ & 0.9994 & 0.9997 & 0.9996 & 0.9993 \\
\hline
\end{tabular}

[a] Bond lengths for the $\left[\mathrm{Ln}\left(\mathrm{H}_{2} \mathrm{O}\right)_{8}\right]^{3+}$ complexes taken from Ref. 45 .

\section{Gas-phase energetics}

To gain further insight into the reasons behind the stability trends observed for $\mathrm{Ln}^{3+}$ complexes across the $4 \mathrm{f}$ period, we calculated the free energy $\left(\Delta G_{\mathrm{g}}\right)$ for the following reaction [Eq. (3)]:

$$
[\mathrm{La}(\mathbf{L})]^{n+/-_{(\mathrm{g})}}+\mathrm{Ln}^{3+}(\mathrm{g}) \rightarrow[\mathrm{Ln}(\mathbf{L})]^{n+/-}{ }_{(\mathrm{g})}+\mathrm{La}^{3+}(\mathrm{g})
$$

in which $\mathbf{L}$ represents a given ligand $\left(\mathrm{BCAED}^{4-}\right.$, $\mathrm{TETA}^{4-}$, or $\mathrm{BP} 18 \mathrm{C}^{2-}$ ) and $\mathrm{Ln}$ refers to different lanthanides across the series $(\mathrm{Ce}, \mathrm{Nd}, \mathrm{Gd}, \mathrm{Tm}$, or $\mathrm{Lu}$ ). The results are shown in Table 3 and Figure $\mathrm{S} 3$ (see the Supporting Information).

The $\Delta G_{\mathrm{g}}$ values given in Table 3 include BSSE corrections that arise from the formation of the Ln-donor bonds of $[\operatorname{Ln}(\mathbf{L})]^{n+/}$ and the breaking of the La-donor bonds in the $\mathrm{La}^{3+}$ analogue. BSSEs were found to decrease along the lanthanide series from $\mathrm{La}$ to $\mathrm{Lu}$ as a consequence of the contraction of the $\mathrm{Ln}^{3+}$ valence orbitals (Table S4 in the Supporting Information). However, we notice that this variation is not completely uniform, and, for instance, $\mathrm{Tm}^{3+}$ complexes give smaller BSSEs than their $\mathrm{Lu}^{3+}$ counterparts. The overall change in BSSE energy across the series from $\mathrm{La}$ to $\mathrm{Lu}$ is significant and amounts to 5.35, 6.05, and 2.39 $\mathrm{kcal} \mathrm{mol}^{-1}$ for $\mathrm{TETA}^{4-}, \mathrm{BCAED}^{4-}$, and $\mathrm{BP} 18 \mathrm{C}^{2-}$ complexes, respectively.

Our calculations show that $\Delta G_{\mathrm{g}}$ values become more negative on proceeding to the right across the lanthanide series for the three series of complexes, which is a consequence of the increased charge density of the metal ion (Figure S3 in the Supporting Information). Although the overall free-energy change across the series from $\mathrm{La}$ to $\mathrm{Lu}$ varies in the order BCAED>TETA>BP18C6, the results indicate that in the gas phase the three series of complexes should increase their stabilities across the $4 \mathrm{f}$ period. We therefore conclude that solvent effects play a crucial role in the observed experimental stability trends. 
Table 3. Calculated solvation free energies and Gibbs free energies for Equations (3) and (4) [kcal mol $\left.{ }^{-1}\right]$.

\begin{tabular}{|c|c|c|c|c|c|}
\hline & & $\Delta G_{\mathrm{g}}{ }^{\text {[a] }}$ & $\Delta G_{\mathrm{sol}}(\mathrm{Ln} \mathbf{L})$ & $\Delta G_{\mathrm{aq}}{ }^{\text {calc }}$ & $\Delta G_{\mathrm{aq}}{ }^{\operatorname{exptl}[\mathrm{b}]}$ \\
\hline \multirow[t]{6}{*}{ TETA $^{4-}$} & $\mathrm{La}$ & 0.00 & -92.25 & 0.00 & - \\
\hline & $\mathrm{Ce}$ & -10.71 & -92.78 & 3.06 & - \\
\hline & $\mathrm{Nd}$ & -28.87 & -92.38 & -0.60 & - \\
\hline & Gd & -60.78 & -92.54 & -3.97 & $-3.27^{[\mathrm{c}]}$ \\
\hline & $\mathrm{Tm}$ & -96.13 & -91.61 & -6.29 & - \\
\hline & $\mathrm{Lu}$ & -107.82 & -91.19 & -6.76 & - \\
\hline \multirow[t]{6}{*}{$\mathrm{BCAED}^{4-}$} & $\mathrm{La}$ & 0.00 & -82.57 & 0.00 & - \\
\hline & $\mathrm{Ce}$ & -11.02 & -82.60 & 3.25 & - \\
\hline & $\mathrm{Nd}$ & -29.91 & -81.38 & -0.32 & -2.84 \\
\hline & $\mathrm{Gd}$ & -63.73 & -79.53 & -3.59 & -5.98 \\
\hline & $\mathrm{Tm}$ & -102.22 & -78.65 & -9.10 & - \\
\hline & $\mathrm{Lu}$ & -114.70 & -78.47 & -10.60 & -11.21 \\
\hline \multirow[t]{6}{*}{$\mathrm{BP} 18 \mathrm{C}^{2-}$} & $\mathrm{La}$ & 0.00 & -66.71 & 0.00 & - \\
\hline & $\mathrm{Ce}$ & -9.82 & -67.32 & 3.87 & -0.16 \\
\hline & $\mathrm{Nd}$ & -23.99 & -66.80 & 4.32 & 0.86 \\
\hline & $\mathrm{Gd}$ & -50.23 & -66.06 & 7.52 & 2.67 \\
\hline & $\mathrm{Tm}$ & -79.18 & -66.40 & 10.33 & 7.37 \\
\hline & $\mathrm{Lu}$ & -88.89 & -66.69 & 11.13 & 9.20 \\
\hline
\end{tabular}

[a] BSSE corrections taken into account with the counterpoise method. [b] Calculated using $\Delta G=-R T \ln K$ and the equilibrium constants given in Figure 1 (determined at 298 $\mathrm{K})$. [c] Value obtained for the Eu complex.

\section{$\underline{\text { Energetics in aqueous solutions }}$}

The evolution of the stability of $[\operatorname{Ln}(\mathrm{TETA})]^{-},[\operatorname{Ln}(\mathrm{BCAED})]^{-}$, and $[\operatorname{Ln}(\mathrm{BP} 18 \mathrm{C} 6)]^{+}$complexes along the lanthanide series in aqueous solutions was evaluated by calculating the Gibbs energy for Equation (4) from the thermodynamic cycle presented in Scheme 2.

$$
[\mathrm{La}(\mathbf{L})]^{n+/-}{ }_{(\text {sol })}+\mathrm{Ln}_{(\text {(sol })}^{3+} \rightarrow[\operatorname{Ln}(\mathbf{L})]^{n+/-}{ }_{(\text {sol })}+\mathrm{La}^{3+}{ }_{(\text {sol })}
$$

Thus, the Gibbs free energy for Equation (4) was computed as Equation (5):

$$
\begin{aligned}
& \Delta G_{\mathrm{aq}}=\Delta G_{\mathrm{g}}+\Delta G_{\mathrm{sol}}\left([\operatorname{Ln}(\mathbf{L})]^{n+/-}\right)+\Delta G_{\mathrm{sol}}\left(\mathrm{La}^{3+}\right)-\Delta G_{\mathrm{sol}}\left(\mathrm{Ln}^{3+}\right)- \\
& \Delta G_{\mathrm{sol}}\left([\mathrm{La}(\mathbf{L})]^{n+/-}\right)
\end{aligned}
$$




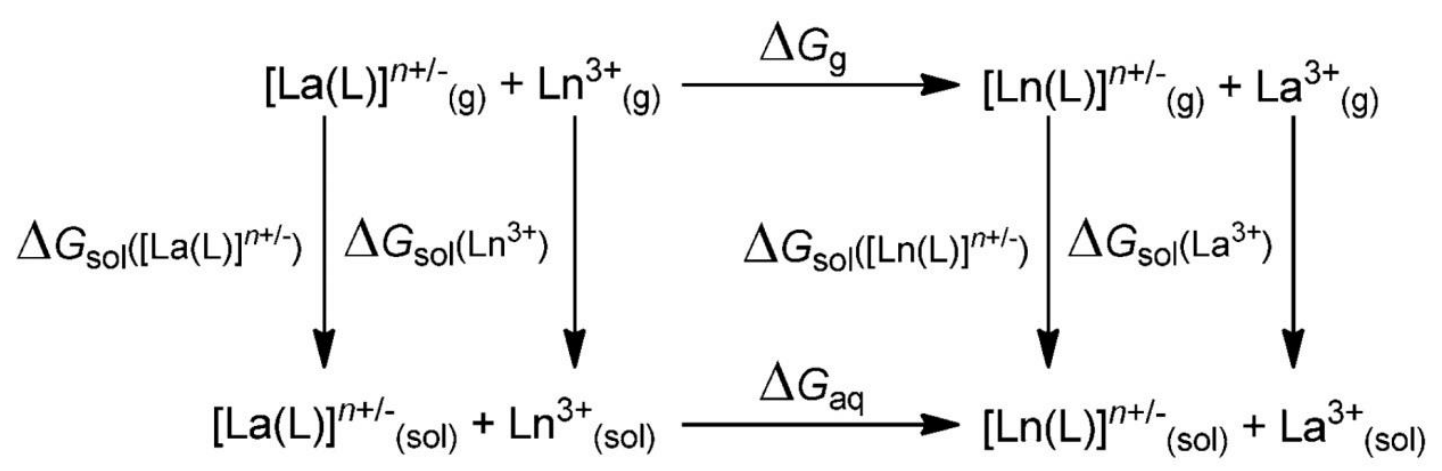

Scheme 2.

The calculated hydration free energies of the different complexes as well as the computed $\Delta G_{\text {aq }}$ values are shown in Figure 5 and Table 3. As expected on account of their similar structure, hydration free energies do not vary significantly across the lanthanide series for complexes with a given ligand. The hydration energies vary in the following order: $[\operatorname{Ln}(\mathrm{TETA})]^{-}>[\mathrm{Ln}(\mathrm{BCAED})]^{-}>[\mathrm{Ln}(\mathrm{BP} 18 \mathrm{C} 6)]^{+}$. The electrostatic potential on the molecular surface of [Gd(TETA) $]^{-}$(Figure 6) shows that the surface of the complex ${ }^{[46]}$ can be divided in two regions: a hydrophilic region that contains the carboxylate groups and is characterized by a negative electrostatic potential, and a hydrophobic hemisphere on the opposite side of the chelate, as noticed previously for related systems. ${ }^{[47]}$ In the case of $[\operatorname{Ln}(\mathrm{BCAED})]^{-}$complexes, the negatively charged groups of the ligand point to different sides of the molecule, which results in a lower negative electrostatic potential that is spread over a larger portion of the molecular surface. Finally, the surface of $[\mathrm{Ln}(\mathrm{BP} 18 \mathrm{C} 6)]^{+}$is characterized by a smaller negative electrostatic potential that occupies a small region of the molecular surface, as expected on account of the reduced number of carboxylate groups of the ligand.

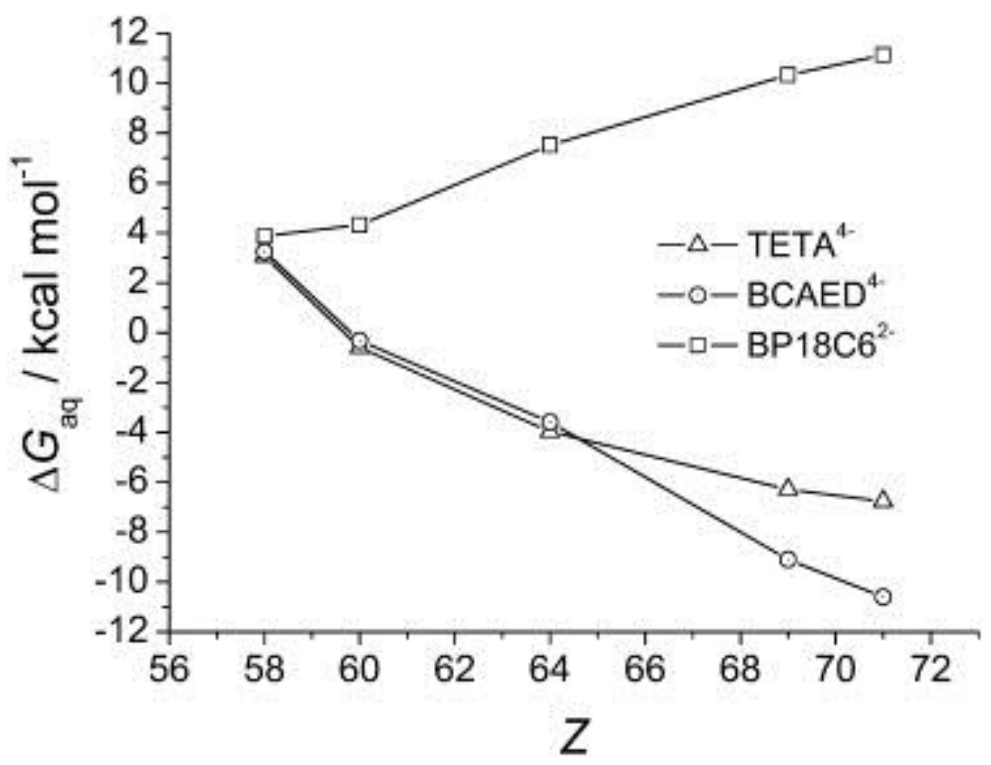

Figure 5. Gibbs free energies computed for Equation (4) in aqueous solutions.

Our calculations provide Gibbs free energies in aqueous solution that are in very good agreement with the experimental stability trends (Figure 5). Since hydration energies do not change substantially for a given series of $\mathrm{Ln}^{3+}$ complexes, the different stability trends observed across the $4 \mathrm{f}$ period are the result of a subtle 
balance between two factors: 1) The increasing hydration free energies of the $\mathrm{Ln}^{3+}$ ions across the series owing to their increased charge density, and 2) the increasing binding energy of the ligand to the metal ion across the series reflected in the calculated $\Delta G_{\mathrm{g}}$ values. Since most polyaminocarboxylate ligands are better ligands for the $\mathrm{Ln}^{3+}$ ions than water, in the absence of increasing steric constraints for the coordination of the $\mathrm{Ln}^{3+}$ ions across the series, the $\Delta G_{\mathrm{g}}$ values clearly compensate the increasing hydration energies of the cations. As a result, most complexes with polyaminocarboxylate ligands show an increasing stability along the $4 \mathrm{f}$ series. This is the case of $[\operatorname{Ln}(\mathrm{TETA})]^{-}$complexes, and particularly of the $[\operatorname{Ln}(\mathrm{BCAED})]^{-}$analogues.
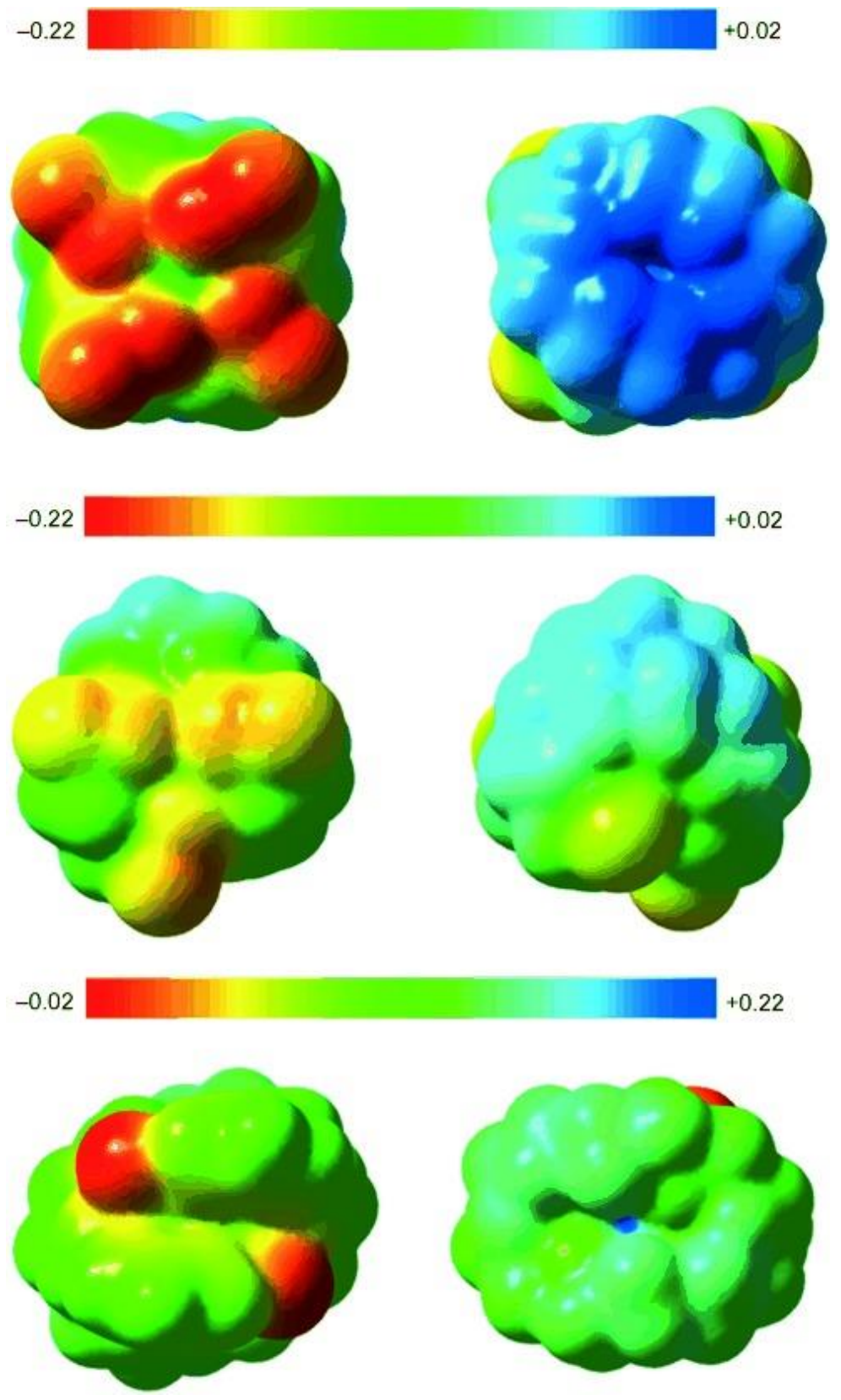

Figure 6. Computed TPSSh/LCRECP/6-31G(d,p) electrostatic potential (hartree) of [Gd(TETA)] ${ }^{-}$(top), $[\mathrm{Gd}(\mathrm{BCAED})]^{-}$(middle), and [Gd(BP18C6) $]^{+}$(bottom) on the molecular surfaces defined by 0.001 electrons bohr ${ }^{-3}$ contours of the electron density. Note the different scale used for [Gd(BP18C6) $]^{+}$.

However, the situation is different for $[\operatorname{Ln}(\mathrm{BP} 18 \mathrm{C} 6)]^{+}$complexes, in which the ligand is particularly well suited for the coordination of the large $\mathrm{Ln}^{3+}$ ions. In this system, the increasing $\Delta G_{\mathrm{g}}$ values cannot 
compensate the increasing hydration free energies upon a decrease in the ionic radius of the metal ion, which results in an unusual drop in complex stability across the $4 \mathrm{f}$ series.

A comparison between the energetic trends shown in Figures 1 and 5 clearly provide evidence of a gratifying qualitative agreement between the experimental and calculated trends. To further check the validity of our approach, we have calculated the experimental $\Delta G_{\text {aq }}$ values from the equilibrium constants determined experimentally using potentiometric measurements. ${ }^{[11,15,20]}$ A comparison of the two sets of data (Table 3) provides evidence of a satisfactory agreement between them, particularly if one considers: 1) the experimental errors in both stability constants and hydration free energies of the $\mathrm{Ln}^{3+}$ ions; 2) the effect of the electrolyte used to keep the ionic strength for potentiometric measurements constant; and 3) the intrinsic errors associated with the computational methodology used (density functional, basis sets, solvation model, and so forth).

\section{Conclusion}

We have developed a computational approach that allows a rational analysis of the stability trends of lanthanide complexes along the $4 \mathrm{f}$ period. The optimized structures of three representative series of $\operatorname{Ln}^{3+}$ complexes provide evidence of a quadratic decrease of the average Ln-donor distances across the series. We have shown that the parameters obtained from the fittings of these geometrical data may be used to assess the degree of increasing steric compression around the metal ion across the series. The subsequent energetic analysis performed for the three series of complexes not only provides a qualitative justification of the observed stability trends, but also gives a fairly good quantitative agreement with the experimental results. Since hydration free energies of isostructural $\mathrm{Ln}^{3+}$ complexes do not change substantially across the series, the overall stability trend is mainly determined by the increased electrostatic interaction between the ligand and the metal ion across the $4 \mathrm{f}$ series, and to what extent this contribution compensates the more negative hydration energies of the $\mathrm{Ln}^{3+}$ ion. Owing to the difficulties associated with the separation and purification of the $\mathrm{Ln}^{3+}$ ions, the results reported here represent a significant advance for the prediction of stability trends of lanthanide complexes, with great potential impact for the design of more efficient ligands for $\mathrm{Ln}^{3+}$ discrimination. Furthermore, the same computational approach could be in principle extended to any set of related metal complexes with primarily electrostatic metal-ligand bonds (i.e., alkaline, alkaline-earth, or actinide ions), with great potential impact on the rationalization and prediction of their coordination chemistry.

\section{Acknowledgements}

Authors thank the Centro de Supercomputación de Galicia (CESGA) for providing the computer facilities. The financial support of the Xunta de Galicia (CN2012/011) and the Universidade da Coruña is also gratefully acknowledged.

\section{References}

[1] R. D. Hancock, Chem. Soc. Rev. 2013, 42, 1500-1524.

[2] E. Brücher, G. Tircso, Z. Baranyai, Z. Kovacs, A. D. Sherry, Stability and Toxicity of Contrast Agents in The Chemistry of Contrast Agents in Medical Magnetic Resonante Imaging, 2nd ed. (Eds.: A. E. Merbach, L. Helm, É. Tóth), Wiley, Hoboken, 2013, pp. 157-201. 
[3] a) M. Blanusa, V. M. Varnai, M. Piasek, K. Kostial, Curr. Med. Chem. 2005, 12, 2771-2794; b) O. Andersen, Chem. Rev. 1999, 99, 2683-2710; c) O. Andersen, Mini-Rev. Med. Chem. 2004, 4, 11-21.

[4] a) S. G. Galbraith, P. A. Tasker, Supramol. Chem. 2005, 17, 191-207; b) D. S. Flett, J. Organomet. Chem. 2005, 690, 2426-2438.

[5] a) S. Leguay, T. Vercouter, S. Topin, D. Guillaumont, M. Miguirdichian, P. Moisy, C. Le Naour, Inorg. Chem. 2012, 51, 12638-12649; b) X. Cao, D. Heidelberg, J. Ciupka, M. Dolg, Inorg. Chem. 2010, 49, $10307-10315$.

[6] R. G. Pearson, J. Am. Chem. Soc. 1963, 85, 3533-3539.

[7] R. D. Shannon, Acta Crystallogr. Sect. A 1976, 32, 751-767.

[8] a) H. H. Dam, D. N. Reinhoudt, W. Verboom, Chem. Soc. Rev. 2007, 36, 367-377; b) J.-H. Lan, W.-Q. Shi, L.-Y. Yuan, J. Li, Y.-L. Zhao, Z.-F. Chai, Coord. Chem. Rev. 2012, 256, 1406-1417; c) S. Ozçubukçu, K. Mandal, S. Wegner, M. P. Jensen, C. He, Inorg. Chem. 2011, 50, 7937-7939.

[9] P. Caravan, J. J. Ellinson, T. J. McMurry, R. B. Lauffer, Chem. Rev. 1999, 99, 2293-2352.

[10] R. G. Lacoste, G. V. Chirstoffers, A. E. Martell, J. Am. Chem. Soc. 1965, 87, 2385-2388.

[11] L. Tei, Z. Baranyai, E. Brucher, C. Cassino, F. Demicheli, N. Masciocchi, G. B. Giovenzana, M. Botta, Inorg. Chem. 2010, 49, 616-625.

[12] L. Sarka, I. Banyai, E. Brucher, R. Kiraly, J. Platzek, B. Raduchel, H. Schmitt-Willich, J. Chem. Soc. Dalton Trans. 2000, 3699-3703.

[13] a) C. A. Chang, M. E. Rowland, Inorg. Chem. 1983, 22, 3866-3869; b) E. Brücher, B. Gyori, J. Emri, P. Solymosi, L. B. Sztanyik, L. Varga, J. Chem. Soc. Chem. Commun. 1993, 574-575.

[14] a) A. Roca-Sabio, M. Mato-Iglesias, D. Esteban-Gómez, A. de Blas, T. Rodríguez-Blas, C. PlatasIglesias, Dalton Trans. 2011, 40, 384-392; b) C. A. Chang, V. O. Ochaya, Inorg. Chem. 1986, 25, 355-358.

[15] A. Roca-Sabio, M. Mato-Iglesias, D. Esteban-Gómez, É. Tóth, A. de Blas, C. Platas-Iglesias, T. Rodríguez-Blas, J. Am. Chem. Soc. 2009, 131, 3331-3341.

[16] J. D. L. Dutra, M. A. M. Filho, G. B. Rocha, R. O. Freire, A. M. Simas, J. J. P. Stewart, J. Chem. Theory Comput. 2013, 9, 3333-3341.

[17] a) M. Barysz, Y. Ishikawa, Relativistic Methods for Chemists, Springer, New York, 2010; b) P. Pyykko, Chem. Rev. 1988, 88, 563-594; c) M. Ferbinteanu, T. Kajiwara, K.-Y. Choi, H. Nojiri, A. Nakamoto, N. Kojima, F. Cimpoesu, Y. Fujimura, S. Takaishi, M. Yamashita, J. Am. Chem. Soc. 2006, 128, 9008-9009.

[18] M. Dolg, X. Cao, Chem. Rev. 2012, 112, 403-480.

[19] M. F. Loncin, J. F. Desreux, E. Merciny, Inorg. Chem. 1986, 25, 2646-2648.

[20] E. T. Clarke, A. E. Martell, Inorg. Chim. Acta 1991, 190, 37-46.

[21] M.-R. Spirlet, J. Rebizant, M.-F. Loncin, J. F. Desreux, Inorg. Chem. 1984, 23, 4278-4283.

[22] J.-G. Kang, M.-K. Na, S.-K. Yoon, Y. Sohn, Y.-D. Kim, I.-H. Suh, Inorg. Chim. Acta 2000, 310, 56-64. 
[23]J. M. Tao, J. P. Perdew, V. N. Staroverov, G. E. Scuseria, Phys. Rev. Lett. 2003, 91, 146401/1-146401/4.

[24] Gaussian 09, Revision A.01, M. J. Frisch, G. W. Trucks, H. B. Schlegel, G. E. Scuseria, M. A. Robb, J. R. Cheeseman, G. Scalmani, V. Barone, B. Mennucci, G. A. Petersson, H. Nakatsuji, M. Caricato, X. Li, H. P. Hratchian, A. F. Izmaylov, J. Bloino, G. Zheng, J. L. Sonnenberg, M. Hada, M. Ehara, K. Toyota, R. Fukuda, J. Hasegawa, M. Ishida, T. Nakajima, Y. Honda, O. Kitao, H. Nakai, T. Vreven, J. A. Montgomery, Jr., J. E. Peralta, F. Ogliaro, M. Bearpark, J. J. Heyd, E. Brothers, K. N. Kudin, V. N. Staroverov, R. Kobayashi, J. Normand, K. Raghavachari, A. Rendell, J. C. Burant, S. S. Iyengar, J. Tomasi, M. Cossi, N. Rega, J. M. Millam, M. Klene, J. E. Knox, J. B. Cross, V. Bakken, C. Adamo, J. Jaramillo, R. Gomperts, R. E. Stratmann, O. Yazyev, A. J. Austin, R. Cammi, C. Pomelli, J. W. Ochterski, R. L. Martin, K. Morokuma, V. G. Zakrzewski, G. A. Voth, P. Salvador, J. J. Dannenberg, S. Dapprich, A. D. Daniels, Ö. Farkas, J. B. Foresman, J. V. Ortiz, J. Cioslowski, D. J. Fox, Gaussian, Inc., Wallingford CT, 2009.

[25] A. Roca-Sabio, M. Regueiro-Figueroa, D. Esteban-Gómez, A. de Blas, T. Rodríguez-Blas, C. PlatasIglesias, Comput. Theor. Chem. 2012, 999, 93-104.

[26] D. Esteban-Gómez, A. de Blas, T. Rodríguez-Blas, L. Helm, C. Platas-Iglesias, ChemPhysChem 2012, 13, 3640-3650.

[27] M. Dolg, H. Stoll, A. Savin, H. Preuss, Theor. Chim. Acta 1989, 75, 173-194.

[28] a) L. Maron, O. Eisenstein, J. Phys. Chem. A 2000, 104, 7140-7143; b) O. Eisenstein, L. Maron, J. Organomet. Chem. 2002, 647, 190-197.

[29] C. Platas-Iglesias, A. Roca-Sabio, M. Regueiro-Figueroa, D. Esteban-Gómez, A. de Blas, T. RodríguezBlas, Current Inorg. Chem. 2011, 1, 91-116.

[30] C. Platas-Iglesias, Eur. J. Inorg. Chem. 2005, 2023-2033.

[31] J. Tomasi, B. Mennucci, R. Cammi, Chem. Rev. 2005, 105, 2999-3093.

[32] A. V. Marenich, C. J. Cramer, D. G. Truhlar, J. Phys. Chem. B 2009, 113, 6378-6396.

[33] U. Cosentino, A. Villa, D. Pitea, G. Moro, V. Barone, J. Phys. Chem. B 2000, 104, 8001-8007.

[34] R. Guillaumont, F. David, Radiochem. Radioanal. Lett. 1974, 17, 25-39.

[35] D. A. Pantazis, F. Neese, J. Chem. Theory Comput. 2009, 5, 2229-2238.

[36] a) M. Dolg, H. Stoll, H. Preuss, J. Chem. Phys. 1989, 90, 1730-1734; b) energy-consistent ECPs and associated basis sets are available at http://www.theochem.uni-stuttgart.de/index.en.html.

[37] F. Bernardi, S. F. Boys, Mol. Phys. 1970, 19, 553-566.

[38] A. Zawada, R. W. Gora, M. M. Mikolajczyk, W. Bartkowiak, J. Phys. Chem. A 2012, 116, 4409-4416.

[39] a) C. E. Kefalidis, L. Perrin, L. Maron, Eur. J. Inorg. Chem. 2013, 4042-4049; b) B. Kvamme, M. C. F. Wander, A. E. Clark, Int. J. Quantum Chem. 2009, 109, 2474-2481.

[40] U. Cosentino, U. Villa, D. Pitea, G. Moro, V. Barone, A. Maiocchi, J. Am. Chem. Soc. 2002, 124, 49014909.

[41] M. Purgel, Z. Baranyai, A. de Blas, T. Rodríguez-Blas, I. Banyai, C. Platas-Iglesias, I. Tóth, Inorg. Chem. 2010, 49, 4370-4382. 
[42] a) F. Mayer, C. Platas-Iglesias, L. Helm, J. A. Peters, K. Djanashvili, Inorg. Chem. 2012, 51, 170-178; b) L. M. P. Lima, A. Lecointre, J.-F. Morfin, A. de Blas, D. Visvikis, L. J. Charbonnière, C. Platas-Iglesias, R. Tripier, Inorg. Chem. 2011, 50, 12508-12521; c) Z. Baranyai, M. Botta, M. Fekete, G. B. Giovenzana, R. Negri, L. Tei, C. Platas-Iglesias, Chem. Eur. J. 2012, 18, 7680-7685; d) P. D'Angelo, R. Spezia, Chem. Eur. J. 2012, 18, 11162-11178.

[43] M. Seitz, A. G. Oliver, K. N. Raymond, J. Am. Chem. Soc. 2007, 129, 351-353.

[44] J. Kuta, A. E. Clark, Inorg. Chem. 2010, 49, 7808-7817.

[45] K. Djanashvili, C. Platas-Iglesias, J. A. Peters, Dalton Trans. 2008, 602-607.

[46] Electrostatic potentials were calculated on the molecular surfaces defined by the 0.001 electrons bohr ${ }^{-3}$ contour of the electron density. R. F. W. Bader, M. T. Carroll, J. R. Cheeseman, C. Chang, J. Am. Chem. Soc. 1987, 109, 7968-7979.

[47] a) A. Borel, L. Helm, A. E. Merbach, Chem. Eur. J. 2001, 7, 600-610; b) E. M. López-Vidal, M. Regueiro-Figueroa, M. D. García, C. Platas-Iglesias, C. Peinador, J. M. Quintela, Inorg. Chem. 2012, 51, $4429-4431$.

\footnotetext{
${ }^{\mathrm{i}}$ Supporting information for this article is available online: https://doi.org/10.1002/chem.201304469.
} 